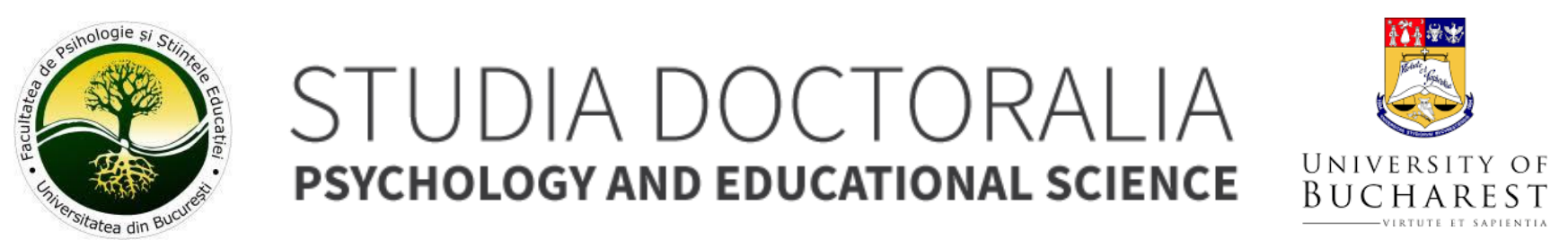

\title{
The role of personality in the relationship between the perceived parenting style and the choice of coping mechanisms
}

\author{
Maria Popescu
}

University of Bucharest

\section{ARTICLE INFO}

Article history:

Received 20-June-2020

Accepted 25-July-2020

Available online 01-November-2020

This article should be cited as: Popescu, M. (2020). The role of personality in the relationship between the perceived parenting style and the choice of coping mechanisms. Studia Doctoralia. Psychology and Educational Science, 11(2), 93-109. https://doi.org/10.47040/sd/sdpsych.v11i2.115

This is an open access article under the CC BY license (http://creativecommons.org/licenses/by/4.0/).

Corresponding author at: University of Bucharest, Department of Psychology, 90 Panduri Av, Bucharest, $\mathrm{RO}$.

Tel.: +40 (0) 31-425.34.45

E-mail address: mariapopescu1234@gmail.com

\section{ABSTRACT}

This study examined the moderating role of personality in the relationship between perceived parenting type and personal coping style. One hundred and fourteen women and 30 men, aged between 16 and 71 years old, participated in the present study. The instruments used were the Parenting Style Inventory-II (PSI-II), the COPE inventory, and Big-Five IPIP-50. Results showed that social coping was the only coping style that was significantly predicted by parenting dimensions. It was found that extraversion negatively moderates the relationship between mothers' and, respectively, fathers' parenting styles and social coping. Emotional stability also negatively moderates the link between parenting and social coping, but only for the mother's parenting. When analysed the separate dimensions of the parenting styles, it was found that emotional stability also negatively moderates the relationship between mother's, respectively father's warmth and social coping. Agreeableness was found to moderate the positive link between maternal parenting style and social coping, more specifically, maternal control. Openness to experience negatively moderated the relationship between maternal warmth and social coping. No significant relationships were found for conscientiousness. The present study can contribute to clinical practice by the insight it provides on the interaction between personality and environmental factors in the development of coping styles. This information can be used in tailoring the psychological interventions so that they can best suit each personality type. 


\section{INTRODUCTION}

The primary concern of clinical psychology and psychotherapy is to find solutions to improve or preserve mental health. For these interventions to be effective, a thorough and complete knowledge of the factors influencing mental health is needed. One of them is coping, defined as the individual's response to stress caused by situations perceived as threatening and having direct effects on mental functioning.

Since stressors are often impossible to control, mental health professionals should focus on ways to increase the effectiveness of the customer's coping mechanisms so that they can act directly on the situation or diminish the psychological pressure that the context inflicts on them.

Personality has also been linked to mental health (e.g.: Su et al., 2018; Hakulinen et al., 2015, apud. Cramer et al., 2015), since the experimentation of negative emotions is often a predisposition manifested through neurotic traits, just as the state of well being is correlated with extraversion. There is also plenty of evidence that personality traits determine the choice of coping mechanisms (Connor-Smith \& Flachsbart, 2007, apud. Gárriz et al., 2015). In practice, these conclusions point out that any intervention based on learning adaptive coping mechanisms must be based on knowledge of the personality structure of the client, which will determine the ease and effectiveness of implementing these strategies, as well as the dysfunctional patterns and potentially dangerous situations that the client is prone to exposing themselves to (conflicts, risk behaviour, etc.).

Previous research shows that a key agent in determining the predominant coping style is the parental style that the individual experienced during their childhood (Nijhof \& Engels, 2007; Wolfradt et al., 2003). One of the reasons behind this association is that a positive relationship with one's parents can be an important source of social support for young people, from which they can develop resources such as self-esteem (Cohen \& Wills, 1985; Baumunand, 1991, apud. Wolfradt et al., 2003). Most of these studies focus on the population of adolescents or young adults, especially students, who face age-related challenges, such as anxiety and depersonalization (Wolfradt et al., 2003), loneliness and homesickness in the case of students (Nijhof \& Engels, 2007) or gambling (Dixon et al., 2016). This study aims to investigate the impact of parental styles in choosing coping mechanisms in more age groups.

Furthermore, while it is widely established that the coping style is partly shaped by parental influences from childhood, the way in which interindividual differences of personality interact with this relationship has not been studied so far. The clarification of this relationship could also have implications in the parenting field, in terms of adapting parental practices to the personality of the child. In other words, the importance of parents' customized psychosocial education is stressed, in order to improve their children's ability to meet the challenges of adverse situations, taking into account their personality predispositions.

\section{Parental Style}

The theoretical model on which most of the literature on parenting is based is Baumrind's model (1967), which differentiates between three distinct parenting styles: there are authoritarian, democratic and permissive parents. Based on this model, McCoby and Martin (1983) have developed a new classification based on two dimensions: the degree of warmth (or responsiveness) the parent offers, along with the degree of control exercised on the child. The combination of these two dimensions leads to a fourth parental style, the negligent one, characterized by a lack of emotional availability and a lack of imposed control. If the child only receives affectivity, but not rules and requirements, the style is a permissive one, whereas, on the contrary, if the parent imposes directions without providing warmth, we are talking about authoritarian style.

The most beneficial parental style for children's development has proved to be the democratic one, characterized by a combination of high warmth and control, with the authors showing effects in many development plans: school performance (Dornbusch et al., 1987), identity formation (Adams \& Jones, 1983; Dusek \& Litovsky, 1988), self-esteem level (Litovsky \& Dussek, 1985), drug use prevention (Becoña et al., 2012) and psychosocial adaptation (Lamborn et al., 1991). According to Steinberg (2001), the efficient functioning outside the family environment is a matter of the individual's ability to form relationships and socially integrate, enhanced by the component of acceptance and involvement and by the limits imposed by the democratic parents.

The authoritarian style, characterized by strict control, in the absence of support and affection, is a predictor of low socio-emotional skills (Parker \& Benson, 2004; Van den Akker et al., 2007, apud. Ayana \& Pérez-Edgar, 2019). The lack of ability to make decisions alone also strengthens the feeling of dependence on the parent. The lack of parental affection prevents the children from assimilating the limits placed on them by the parents (Grusec \& Goodnow, 1994, apud. Zhou et al., 2008), as they perceive them as punitive and disregarding their needs.

In the case of children raised in a permissive way, the outcome that can be observed is having low interpersonal expectations as a result of the parents' pattern of indifferent response to their need for guidance. Studies show that children tend to become dependant on others, have weak social skills, be more self-centred, impulsive and aggressive (Nijhof, \& Engels, 2007) or develop behavioural problems as a result of lack of supervision (Berg-Nielsen, Viktor, \& Dahl, 2002, apud. Robila \& Krishnakumar, 2006). On the other 
hand, the receptiveness to the needs of others that they observe in the family can help develop empathy in children (Davidov \& Grusec, 2006, apud. Zhou, 2008), that reduces externalisation behaviours (Zhou et al., 2002, apud. Zhou et al., 2008).

The most damaging effects are clearly those of negligent parenting, where none of the children's needs is met, causing them to grow up without limits and structure, and without a sense of security and appreciation. Studies show that the impact of this parental style can be manifested through antisocial and aggressive behaviour (Kutson et al., 2004), depression and suicide attempts in the female population (Ehnvall, 2008) and developing eating disorders (Jáuregui et al., 2011).

\section{Coping style}

Coping is defined in the literature as the totality of mechanisms that an individual consciously uses to cope with stressful situations, threats and losses, thus managing to adapt to the continually changing environment (Skinner et al., 2003). Coping can be seen both as a state (situational) and as a feature/style (stable preference for choosing a particular type of strategy).

One of the best known theoretical models of coping in relation to stress was developed by Lazarus (1999), which introduces the concept of "assessment". This refers to the assignment of personal significance to an event, depending on which the most effective coping strategies will be chosen. Thus, depending on our perception of a situation as more or less dangerous or easy to control, we will act accordingly, trying to minimize losses or maximize earnings (Matthews et al., 2015). Based on this model, Lazarus distinguished two categories of coping styles, differentiated by the direction of attention allocation: externally (when efforts are focused on the concrete improvement of the situation, in problemfocused coping) versus internally (through efforts of reducing the negative affects produced by the stressor, in emotion-focused coping). Problem-focused coping includes mechanisms such as planning, problem-solving and eliminating competing activities, while emotional coping is based on cognitive reinterpretation strategies, acceptance of the situation, turning to religion and abstaining from action.

Another distinction was made by Endler and Parker (1990, apud. Matthews et al., 2015), adding the dimension of avoidant coping, characterized by the lack of both action and inward attention orientation. In this case, the individual ignores the situation, thoughts and emotions related to it, as if it were not (Connor-Smith \& Flachsbart, 2007).

Carver and O'Connor (2010) highlight another possible method of categorization, between active (engagement) coping, which includes any action aimed at improving the situation or related emotions, versus passive (disengagement), which refers to mechanisms such as denial, distraction, avoidance and reverie, designated as the most inefficient by the authors; both categories can include both problem-focused and emotion-focused strategies, to which many authors add the dimension of coping through seeking social support (Skinner et al., 2003).

\section{Personality and coping style}

The consensus in the literature is that, in addition to situational factors, the choice of coping mechanisms is also influenced by personality predispositions, which can influence our perception and assessment of stressful situations (Matthews et al., 2015).

The meta-analysis carried out by Connor-Smith and Flachsbart (2007) on 165 studies and 33,094 participants reveal significant positive correlations between neuroticism and the expression of negative emotions (physical or verbal aggressiveness, crying, hostility, etc.), social isolation, reverie and substance abuse (alcohol, nicotine, illegal drugs). Conscientiousness was significantly linked to the use of problem-solving and cognitive restructuring mechanisms, the same as extraversion, which in addition correlates with seeking social support. Agreeableness and openness were weakly correlated to active coping strategies, including the search for social support and emotional adjustment in the case of agreeableness, and problem-solving and cognitive restructuring for openness (Connor-Smith \& Flachsbart, 2007).

In a study investigating the mediator role of coping style in the link between personality and internet addiction (Zhou et al., 2017), it was found that extraversion and openness, personality traits that are usually found to be protective factors, were positively associated with internet addiction, through the effect of emotional coping. The authors justify this relationship through the components of impulsivity (Eysenck \& Eysenck, 1963) and reward sensitivity (Carver \& Connor-Smith, 2010) observed in extraverted people, as well as through the tendencies towards avoidant strategies, such as daydreaming, of people with high openness.

Apart from the choice of coping mechanisms, personality can also determine the individual differences in their effectiveness and the frequency of exposure to potentially risky situations (Bolger \& Zuckerman, 1995). For instance, Bolger and Zuckerman (1995) argue that therapeutic interventions based on reducing the frequency of avoidant coping mechanisms, usually considered maladaptive, result in only a small decrease in distress for neurotic clients or patients, as these strategies protect them from experiencing far stronger negative emotions than other people. In this case, interventions should be based on making existing coping mechanisms more effective rather than replacing them.

\section{Parental style and coping style}

Research shows a significant correlation between parental style an individual has grown up with and the predominant coping style used in adolescence and youth. It is widely recognized that a positive relationship with parents 
is a form of social support necessary to develop selfconfidence and self-effectiveness of adolescents in the face of stressful situations (Cohen \& Wills, 1985; Baumrand, 1991, quoted in Wolfradt et al, 2003).

The attachment theory, formulated by Bowlby (1969, 1973, 1980, apud. Bretherton, 1990) postulate that when parents create a safe environment through their relationship with the child, showing appropriate answers to his needs, the child feels safe to explore the surrounding environment. By contrast, a child brought up by super-protective and restrictive parents (authoritarians, according to the model of McCoby and Martin, 1983) can perceive the world as a frightening place, feeling less confident in exploring the environment. We can assume that such a person, when faced with a stressful event, will not feel that he or she has the necessary resources to use active coping mechanisms.

Moreover, Wagner et al. (1990, apud. Dusek \& Danko, 1994) have shown that coping mechanisms are assimilated through the process of socialization. The study of Dusek and Danko (1994) shows that individuals raised with a democratic or permissive parental style are the most likely to have a problem-focused coping approach, while those raised by negligent parents tend to have a coping style based on cognitive restructuring and the expression of emotions. The study explains these results by the child's perception of the availability of parents, which may lead them to ask for instrumental support from them, but also by the association of the warm parental style with psychological and psychosocial adaptation (Adams \& Jones, 1983; Lamborn et al., 1991; Litovsky \& Dusek, 1988; Wagner et al., 1990; apud Dusek \& Danko, 1994). The study of Clark et al. (2002) argues that the warmth dimension of parenting, which facilitates the development of a close relationship between parents and children, can lead to children learning adaptive mechanisms to solve problems from people around them through the social skills they develop. The dimension of control in the democratic style, together with the emotional support, gives the child the confidence and discipline needed to become autonomous at maturity, as well as the self-efficacy of engaging in active coping mechanisms (Clark et al., 2002). On the other hand, the expression of anger and hostility, observed in authoritarian parenting through scolding and punishments as disciplinary measures, is a predictor for coping through emotional venting or physical or verbal aggression towards others (Garner \& Estep, 2001, apud. Chan, 2010).

Taking into account the above, we establish our first hypothesis:

$\mathrm{H} 1$ : The warmth and control dimensions of the parental styles are significant predictors of the coping strategies.

\section{Parental style and personality}

Studies emphasize the importance of the fit between parental factors and the child's personality, rather than the separate effect on adulthood outcomes (e.g.: Thomas \& Chess, 1977, apud. Prinzie et al., 2012). Personality is the expression of temperament (strongly biologically determined, with expressions visible early onset of life) in interaction with environmental factors that can strengthen or reduce certain temperamental tendencies. For example, the literature refers to the concept of 'negative reactivity', which represents a low biological threshold of stimulation of the punishment systems (Kagan, Reznick, \& Snidman, 1987, apud. Anaya \& Pérez-Edgar, 2019), resulting in a high stimuli sensitivity and a higher predisposition of assessing them as dangerous. In childhood, this is manifested by crying, avoidant behaviour and latency of response. In an environment where these behaviours are reinforced by overly protective parents, this can eventually lead to a high risk of developing anxiety, internalizing behaviour and neurotic traits. This relationship arises in particular in the case of mothers with a high sensitivity to the fear of children, who respond through excessive control in situations of minimal risk, thus altering the social inclusion capacity of the child at pre-school age (Kiel \& Buss, 2011; Kiel \& Buss, 2012, apud. Anaya and Pérez-Edgar, 2019), who would be characterised as authoritarian in the McCoby and Martin (1983) model.

On the other hand, the same article refers to the conclusions of Morales et al. (2016) on 'positive reactivity', which refers to the child's tendency to approach new stimuli with enthusiasm and exuberance. These children have a high threshold of punishment systems stimulation, requiring more stimulation from the environment and showing curiosity rather than fear. If this is reinforced in a family environment that lacks teaching of effortful control and selfregulation of attention, it can later manifest itself through externalizing behaviours associated with low agreeableness and conscientiousness, which can, in turn, lead to aggressiveness and antisocial behaviours (Miller, Lynam, \& Jones, 2008, apud. Anaya \& Pérez, 2019). These kinds of outcomes can be expected from permissive parents, who seldom impose rules on their children.

It has been found that a democratic parenting style, based on responsiveness to the needs of the child and behavioural control, is associated with extroversion, agreeableness, conscientiousness, emotional stability and increased openness (Prinzie et al., 2009, apud. Prinzie et al., 2012).

Furthermore, Myers et al. (1999, apud. Kitamura et al., 2009) discovered that the way people report information about their parents' parental style is also influenced by their personality, people with low trait anxiety (the equivalent of high emotional stability) reporting a more favourable relationship with their father. These findings are relevant in the context of this study, especially since self-report scales where used. 


\section{Parental style, personality and coping}

A longitudinal study carried out on the Chinese population involving 425 first and second-grade children and their mothers investigated the relationship between parental style, child temperament and outsourcing behaviours (Eisenberg, Wolchik, \& Tein, 2008). The results have shown that the authoritarian parenting style predicts an increased level of externalising behaviour, while the democratic one predicts a low level of externalising. The dimensions of the temperament of self-control and expression of anger also predict externalising, both temperament and parental style having effects independent of each other. It has also been shown that the relationship between authoritarian parental style and externalising is mediated by the effectiveness of the coping style and adverse events at school, such as poor academic performance or conflict with colleagues. Thus, the importance of biologically determined factors such as temperament and environmental factors such as parental style, on the outcomes of the child's life, in this case externalising behaviours, is noted. The role of coping as a mediator in this relationship supports the premise of this study, which states that the style of coping is an essential contributor to mental health and that its development is

\section{METHODOLOGY}

\section{Participants and procedure}

A sample of convenience was used, consisting of 144 participants aged 16 to $71, \mathrm{M}=27.04, \mathrm{AS}=11.84 .114$ are female (79\%) and 30 male (21\%). Regarding age, $29(20 \%)$ fall under the age group 16-19 (adolescents), 77 (53\%) under the age group 20-30 (young adults) and the remaining 36 participants $(25 \%)$ are from the age group over 31 (adults). The criterion for participating in the study is for participants to have grown up with both parents in their childhood so that they can respond to both the questions about their mother and father.

The data was collected through the administration of online questionnaires distributed on the social network Facebook. Participants gave their consent to the collection of data, once they were assured that they are confidential and used exclusively for research purposes.

\section{Instruments}

Parental style. For the assessment of the parental style, participants completed items from Parenting style inventory II (PSI-II) (Darling \& Toyokawa, 1997). The questionnaire is a review of the PSI-I, which captures parental styles, making a difference from parental practices. Parental style is defined by Darling and Steinberg (1993, apud. Darling \& Toyokawa, 1997) as an emotional climate created by parents' attitudes toward children, while parental practices consist of specific behaviours. The revisions consist of increasing internal facilitated by the interaction between dispositional and contextual factors. As personality derives from the transactional interaction between the biologically determined temperament and parental responses, also influencing the choice of the coping style, we can theorize that it will have an impact on the interaction between parenting and coping.

Also, as previously noted, the literature still lacks consensus on many aspects regarding the efficiency of each parental style or coping style. The present study proposes the hypothesis that the use of certain coping strategies is deemed adaptive by the one using it based not only on the behaviours the person socialized because of their parents but also on their personality structure. An approach that only focuses on environment or dispositional factors for the understandings of coping style choice would be incomplete. Taking into account the relationships among parental styles, personality factors, and coping styles, we formulate the followinf hypothesis:

$\mathrm{H} 2$ : Personality traits have a moderating effect on the relationship between parenting styles and the personal coping style.

consistency by adding new items, as well as introducing the Likert scale with 5 response options instead of 4 , where $1=$ 'total disagreement' and $5=$ 'total agreement'. The scale has 3 dimensions, namely control, warmth and psychological autonomy granting. Since the model currently recognized in that literature is that of McCoby and Martin (1983) which only includes control and warmth as dimensions, the items for autonomy granting were excluded. Thus, participants with high scores (4 or 5) both in control and in warmth have parents who fall in the democratic category. Those with high scores only on control have authoritarian parents, while high scores only on warmth designate the permissive parents. Lastly, low scores (1 or 2) on both warmth and control signify the presence of negligent parenting. The questionnaire was translated into Romanian and contains items such as: "My mother does not like when I tell her about my problems", "My father and I spend time doing fun things", "I can rely on my father if I have any problems", for the warmth dimension and "My father points out the ways I can improve" and "If I don't behave properly, my mother/father will punish me" for the dimension of control. Since there is not a version of this questionnaire adapted to the Romanian population, the items were translated by the author of the study.

Coping. For the identification of the personal style of coping, the COPE questionnaire validated on the Romanian population (Crasovan \& Sava, 2013) was used. The questionnaire contains 60 questions on how to deal with difficult or stressful situations. Participants are asked to check on a Likert scale from 1 to 4 the extent to which they 
normally use a particular strategy when faced with a high level of stress, where 1 = "usually do not do it at all", $2=$ = I usually use it to a small extent", $3=$ "I usually use it to a medium degree", 4 = "l usually use it to a large extent". The aim is to identify the dispositional tendency rather than behaviours influences by specific contextual factors. Following the confirmatory analysis, the Romanian version of the questionnaire captures 4 intercorrelated factors, just as the version developed by Carver, Scheier and Weintraub (1989): problem-focused coping (active coping, planning and elimination of competing activities), emotional coping (positive reinterpretation, acceptance, orientation toward religion and abstaining from action), coping through the seeking of social support (social-instrumental support, social-emotional support and emotional ventilation through the expression of emotions) and avoidant coping (denial, mental disengagement, behavioural disengagement).

Personality. The personality of the respondents was assessed using the translated version of some items from the Big Five IPIP-50 (IPIP-RO), adapted to the Romanian population by lliescu, Popa and Dimache (2015). The questionnaire contains 50 items based on the five-factor model (FFM) model, that was originally developed by Goldberg (1992). The 5 dimensions measured are extraversion, agreeableness, conscientiousness, emotional stability (the opposite of neuroticism) and intellect (openness to experiences). The participants completed on a scale from 1 to 5 how much each statement matches their perception of themselves.

\section{Research model}

As an independent variable, this study focuses on the parental style perceived by the subject during childhood. The parental style is used both as a nominal variable (with the four dimensions - negligent, permissive, authoritarian, democratic), as well as the two sides of the variable, warmth and control, as continuous variables. In order to test the hypotheses, both maternal and paternal style is used, as well as maternal and paternal warmth and control. The dependant variable upon which the effect of parental style is studied is the style of personal coping in adulthood.

\section{RESULTS}

\section{Descriptive statistics}

Table 1. Descriptive statistics

\begin{tabular}{|c|c|c|c|c|c|c|c|c|c|c|c|c|c|c|c|c|}
\hline & $M$ & AS & $a$ & EX & $A G$ & $\mathrm{CO}$ & ES & $\mathrm{OP}$ & PFC & EMC & SSC & AVC & MW & $M C$ & PW & $\mathrm{PC}$ \\
\hline EX & 33.65 & 7.09 & .81 & 1 & & & & & & & & & & & & \\
\hline$A G$ & 41.21 & 5.64 & .79 & $.16^{*}$ & 1 & & & & & & & & & & & \\
\hline $\mathrm{CO}$ & 36.08 & 6.55 & .80 & -.04 & .05 & 1 & & & & & & & & & & \\
\hline ES & 30.82 & 8.46 & .80 & $.50^{* *}$ & .10 & .15 & 1 & & & & & & & & & \\
\hline OP & 40.74 & 5.26 & .87 & $.30^{* *}$ & .15 & .07 & $.20^{*}$ & 1 & & & & & & & & \\
\hline PFC & 35.47 & 5.57 & .88 & $.27^{* *}$ & .16 & $.35^{* *}$ & $.36^{* *}$ & $.24^{* *}$ & 1 & & & & & & & \\
\hline EMC & 41.46 & 5.21 & .78 & -.10 & .12 & $.19^{*}$ & .06 & .02 & $.29^{* *}$ & 1 & & & & & & \\
\hline SSC & 34.88 & 6.85 & .80 & $\begin{array}{c}.23^{* *} \\
-\end{array}$ & $.24^{* *}$ & $\begin{array}{c}-.08 \\
-\end{array}$ & $\begin{array}{c}-.13 \\
-\end{array}$ & -.01 & $\begin{array}{c}.11 \\
-\end{array}$ & $.23^{* *}$ & 1 & & & & & \\
\hline AVC & 26.12 & 5.21 & .82 & $.30^{* *}$ & .04 & $.22^{* * *}$ & $.49^{* *}$ & -.10 & $.38^{* *}$ & .16 & .10 & 1 & & & & \\
\hline MW & 19.66 & 4.41 & .79 & $.18^{*}$ & $.33^{* *}$ & .06 & .12 & .06 & .06 & .11 & $.26^{* *}$ & -.04 & 1 & & & \\
\hline$M C$ & 14.60 & 3.66 & .78 & -.12 & -.06 & -.04 & -.10 & -.08 & -.02 & .02 & .03 & -.04 & $.32^{* *}$ & 1 & & \\
\hline PW & 16.24 & 4.83 & .69 & .09 & .07 & .06 & .16 & .01 & .03 & -.01 & -.02 & .02 & $.17^{*}$ & .01 & 1 & \\
\hline PC & 14.47 & 4.01 & .66 & -.03 & .01 & .11 & .07 & -.07 & .11 & .08 & -.09 & -.13 & -.08 & $.28^{* *}$ & .02 & 1 \\
\hline
\end{tabular}

${ }^{*}$.
$E X=.01,{ }^{*} . p<.05$ $\mathrm{SSC}=$ Social coping, $\mathrm{AVC}=$ Avoidant coping, $\mathrm{MW}=$ Maternal warmth, $\mathrm{MC}=$ Maternal control, $\mathrm{PW}=$ Parental warmth, $\mathrm{PC}=$ Parental control

\section{Hypotheses testing}

For testing the hypotheses, the statistic analysis program PASW Statistics for Windows, Version 18.0. (SPSS Inc., 2009) and the medmod module from Jamovi (The jamovi project, 2019) were used.

$\mathrm{H} 1$ : The warmth and control dimensions of the parental styles are significant predictors of the participants' coping strategies.
In order to test this hypothesis, a series of multiple linear regression analyzes were carried out using as predictors the two components of the parental styles, for the mother and the father (mother's warmth, mother's control, father's warmth, father's control) and, alternatively, the four coping styles (problem-focused, social, emotional and avoidant). 
Table 2. Regression analysis for the dimensions of the parental styles as predictors for the problem-focused coping

\begin{tabular}{|c|c|c|c|c|c|c|}
\hline & & B & Std. Error & Beta & $t$ & $p$ \\
\hline \multirow[t]{5}{*}{1} & (Constant) & 32,20 & 3,76 & & 8,55 & ,00 \\
\hline & MW & ,07 & 11 & ,06 & 61 &, 54 \\
\hline & $M C$ &,- 06 & 14 &,- 04 &,- 41 & 68 \\
\hline & PW & ,02 & ,09 & ,02 & ,19 & 84 \\
\hline & PC & 17 & 12 & ,12 & 1,37 & 17 \\
\hline
\end{tabular}
a. Dependent Variable: problem-focused coping
b. $R^{2}=.02$

The four components of parental styles are not responsible for problem-centred coping variation, with the regression equation being statistically insignificant $(p>.05)$.

Table 3. Regression analysis for the dimensions of the parental styles as predictors for the social coping

\begin{tabular}{|c|c|c|c|c|c|c|}
\hline & & B & Std. Error & Beta & $\mathrm{t}$ & $p$ \\
\hline \multirow[t]{5}{*}{1} & (Constant) & 25.20 & 4.43 & & 5.70 & .00 \\
\hline & MW & .50 & .13 & 32 & 3.70 & .00 \\
\hline & $M C$ & .30 & .17 & 16 & 1.84 & .07 \\
\hline & PW & -.11 & .12 & -.07 & -.91 & .36 \\
\hline & PC & -.20 & .14 & -.11 & -1.33 & .19 \\
\hline
\end{tabular}
a. Dependent Variable: social coping
b. $R^{2}=.10$

The four components of the parental styles are responsible for $10 \%$ of the variation of social coping, with the regression equation being statiscally significant $F(4,139)=3.89$, p. $<$
01. Of the four components of parental styles, only maternal warmth predicts social coping independently, $\beta=.32, \mathrm{t}(144)$ $=3.69, p<.01$.

Table 4. Regression analysis for the dimensions of the parental styles as predictors for the emotional coping

\begin{tabular}{rlrrrrr}
\hline & & B & Std. Error & Beta & $\mathrm{t}$ & $\mathrm{p}$ \\
\hline 1 & (Constant) & 36.43 & 3.51 & & 10.37 & .00 \\
& MW & .16 & .11 & .14 & 1.55 & .12 \\
MC & .06 & .13 & .04 & .44 & .66 \\
PW & -.04 & .09 & -.03 & -.40 & .70 \\
& .11 & .11 & .08 & .93 & .35 \\
\hline
\end{tabular}
a. Dependent Variable: emotional coping
b. $R^{2}=.02$

The four components of parental styles are not responsible for emotional coping variation, the regression equation being statistically insignificant $(p>.05)$.

Table 5. Regression analysis for the dimensions of the parental styles as predictors for the avoidant coping

\begin{tabular}{rlrrrrr}
\hline & & $\mathrm{B}$ & Std. E & & $\mathrm{t}$ & $\mathrm{p}$ \\
\hline 1 & (Constant) & 29.96 & 3.51 & & 8.52 & .00 \\
& MW & -.07 & .11 & -.06 & -.70 & .49 \\
MC & -.03 & .13 & -.02 & -.22 & .82 \\
& .03 & .09 & .03 & .35 & .73 \\
& PW & .11 & -.13 & -1.50 & .14 \\
\hline
\end{tabular}
a. Dependent Variable: avoidant coping
b. $\mathrm{R}^{2}=.02$ 
The four components of parental styles are not responsible for avoidant coping variation either, the regression equation being statistically insignificant $(p>.05)$.

We can state that hypothesis $\mathrm{H} 1$ is only partially supported by analyzed data.

H2: Personality traits have a moderating effect on the relationship between parenting styles and the personal coping style.

H2.1: Extraversion has a moderating effect on the relationship between parenting styles and the personal coping style.

H2.2: Conscientiousness has a moderating effect on the relationship between parenting styles and the personal coping style.

$\mathrm{H}$ 2.3: Emotional stability has a moderating effect on the relationship between parenting styles and the personal coping style.

H2.4: Agreeableness has a moderating effect on the relationship between parenting styles and the personal coping style.

H2.5: Openness (intellect) has a moderating effect on the relationship between parenting styles and the personal coping style.

For testing this hypothesis, the medmod module from Jamovi 1.1.9.0 was used. The results confirm the moderating role of extraversion, emotional stability and agreeableness, but only for the social coping style.

Table 6 shows the estimate of moderation for extraversion in the relationship between maternal style and social coping style. It can be observed that extraversion moderates the relationship between maternal parental style and coping through seeking social support, the moderation estimate being .-10, Cl95\% (-.17., -.04), Z = -3.04, $p<.01$. At average and high values of extraversion, the relationship is insignificant, while at low values the relationship is growing and the estimation is .98, Cl95\% (.29, 1.70), Z $=2.80, p<$ .01 (Table 7).

The moderating role of extraversion in the relationship between the father's parental style and social coping style was also tested. The relationship was found to be significant, with a moderation estimate of $-.07, \mathrm{Cl} 95 \%(-0.14,-0.006), \mathrm{Z}$ $=-2.13, p<.05$ (Table 8). The link is only significant for the high values of extraversion, with an estimate of $-0.87, \mathrm{Cl} 95 \%$ $(-1.60,-.13), z=2.30, p<.05$ (Table 9).

Thus, the data indicate that extraversion moderates the relationship with social coping differently in the case of paternal and maternal style. The relationship is stronger between the maternal style and the child's introverted personality, these factors making the child use more social coping strategies. In the case of paternal style, the most powerful effect is observed concerning the child's extroversion, a relationship which makes the child less likely to appeal to the help of other people.

Table 6. Moderation estimate for extraversion in the relationship between maternal parenting and social coping

\begin{tabular}{lccccccc}
\hline & & & \multicolumn{2}{c}{$95 \%$ C.I. } & & \\
\cline { 5 - 6 } & Estimate & SE & Min & Max & Z & p \\
\hline Maternal parenting & .24 & .25 & -.26 & .73 & .95 & .34 \\
E & .04 & .04 & -.04 & .11 & .90 & .37 \\
Maternal parenting $* \mathrm{E}$ & -.10 & .03 & -.17 & -.04 & -3.04 & .00 \\
\hline
\end{tabular}

E-Extraversion

Table 7. Estimations of the relationship between maternal parenting and social coping for different values of extraversion

\begin{tabular}{|c|c|c|c|c|c|c|}
\hline & \multirow[b]{2}{*}{ Estimate } & \multirow[b]{2}{*}{ SE } & \multicolumn{2}{|c|}{ 95\%C.I. } & \multirow[b]{2}{*}{$\mathbf{Z}$} & \multirow[b]{2}{*}{ 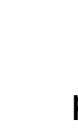 } \\
\hline & & & Min & Max & & \\
\hline Medium & .24 & .26 & -.27 & .75 & .92 & .36 \\
\hline Low (-1SD) & .98 & .36 & .29 & 1.68 & 2.76 & .01 \\
\hline High (+1SD) & -.50 & .36 & -1.22 & .21 & -1.38 & .16 \\
\hline
\end{tabular}




\begin{tabular}{lrrrrrrr}
\hline & & & \multicolumn{2}{c}{$95 \%$ C.I. } & & \\
& Estimate & SE & Min & Max & & Z & p \\
\hline Paternal parenting & -.33 & .26 & -.84 & .17 & -1.30 & .19 \\
E & .04 & .04 & -.03 & .12 & 1.09 & .28 \\
Paternal parenting $* \mathrm{E}$ & -.07 & .03 & -.14 & -.01 & -2.13 & .03 \\
\hline
\end{tabular}

E-Extraversion

Table 9. Estimations of the relationship between paternal parenting and social coping for different values of extraversion

\begin{tabular}{|c|c|c|c|c|c|c|}
\hline & \multirow[b]{2}{*}{ Estimate } & \multirow[b]{2}{*}{$\mathrm{SE}$} & \multicolumn{2}{|c|}{ 95\% C.I. } & \multirow[b]{2}{*}{ Z } & \multirow[b]{2}{*}{$p$} \\
\hline & & & Min & Max & & \\
\hline Medium & -.33 & .26 & -.85 & .18 & -1.28 & .20 \\
\hline Low (-1SD) & .20 & .35 & -.45 & .89 & .56 & .57 \\
\hline High (+1SD) & -.87 & .38 & -1.61 & -.13 & -2.31 & .02 \\
\hline
\end{tabular}

Regarding the two dimensions of parental style taken separately, warmth and control, for both the mother and the father, it is observed that their relationship with social coping is very weak and extraversion does not play a moderating role (Table 10).

Table 10. Moderation estimate for extraversion in the relationships between the dimensions of maternal and paternal parenting and social coping

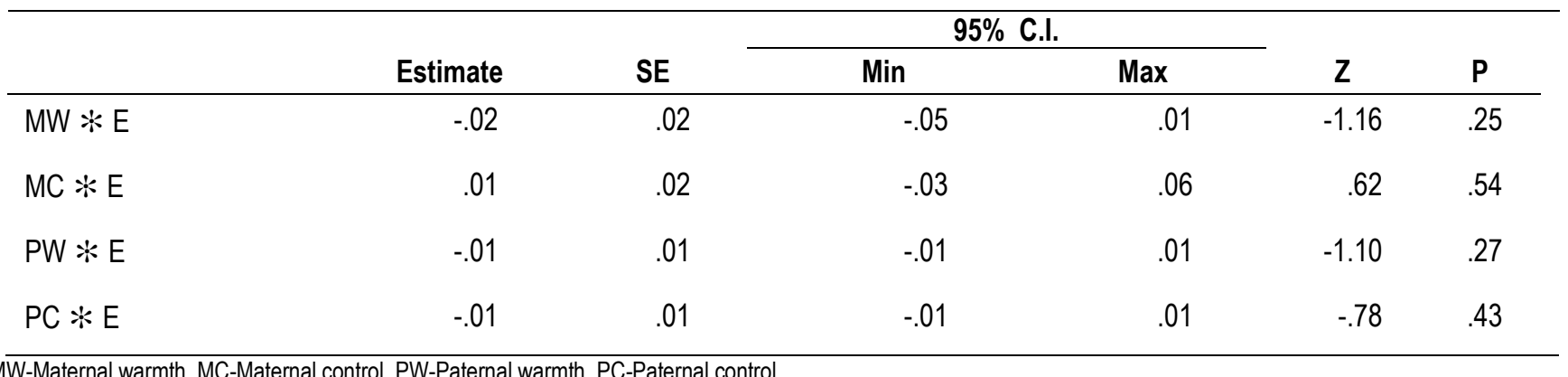

Emotional stability affects the relationship between parenting style and social coping style, but only for mothers, not fathers. For maternal style, the moderation estimate is $.07, \mathrm{Cl} 95 \%$ (-.13, - .008), $z=-2.23, p<.05$ (Table 11). The relationship is not significant for average and increased values of emotional stability, but becomes significant for low values, with a moderation estimate of $-.37, \mathrm{Cl} 95(-1.12, .38)$, $z=-.10, p<.05$ (Table 12). Moreover, the data show a negative moderating effect of emotional stability in the relationship between the warmth of the mother, as well as of the father, and the social coping (Table 13). In the case of mothers, the emotional stability of the participants weakly moderated the relationship between warmth and social coping style with an estimate of $-.05, \mathrm{Cl} 95 \%(-.08,-.02), \mathrm{z}=$ $-3.03, p<.01$. For low and average values of emotional stability, the relationship is significant, but this relationship intensifies for higher values. At an increased level of emotional stability, the estimate of moderation is de -.48 , Cl95\%(-.83, -.14), $z=-2.75, p<.01$ (Table 14). 
Table 11. Moderation estimate for emotional stability in the relationship between maternal parenting and social coping

\begin{tabular}{lccccccc}
\hline & & & \multicolumn{2}{c}{$95 \%$ C.I. } & & \\
\cline { 5 - 6 } & Estimate & SE & Min & Max & Z & p \\
\hline Maternal parenting & .23 & .26 & -.28 & .73 & .89 & .37 \\
ES & .01 & .03 & -.05 & .07 & .33 & .74 \\
Maternal parenting * ES & -.07 & .03 & -.13 & -.01 & -2.22 & .03 \\
\hline
\end{tabular}

ES-Emotional stability

Table 12. Estimations of the relationship between maternal parenting and social coping for different values of emotional stability

\begin{tabular}{lrrrrrr}
\hline & & & \multicolumn{2}{c}{$95 \%$ C.I. } & & \\
\cline { 1 - 3 } Average & Estimate & SE & Min & Max & Z & P \\
Low (-1SD) & .23 & .26 & -.28 & .74 & .90 & .38 \\
High (+1SD) & .83 & .37 & .10 & 1.56 & 2.23 & .03 \\
& -.37 & .38 & -1.12 & .38 & -.10 & .33 \\
\hline
\end{tabular}

Table 13. Estimation of moderation for emotional stability in the relationships between the dimensions of maternal and paternal parenting and social coping

$95 \%$ C.I.

\begin{tabular}{|c|c|c|c|c|c|c|}
\hline & Estimate & SE & Min & Max & $\mathbf{Z}$ & $\mathbf{P}$ \\
\hline MW * & -.05 & .02 & -.08 & -.02 & -3.03 & .00 \\
\hline$M C * E S$ & -.06 & .02 & -.04 & .04 & -.03 & .10 \\
\hline PW * $*$ ES & -.01 & .01 & -.02 & -.08 & 2.00 & 04 \\
\hline$C * E S$ & .01 & .04 & -.01 & .02 & 1.20 & .23 \\
\hline
\end{tabular}

Table 14. Estimations of the relationship between maternal warmth and social coping style for different values of emotional stability

\begin{tabular}{lrrrrrr}
\hline & & \multicolumn{5}{c}{$95 \%$ C.I. } \\
\cline { 4 - 6 } & Estimate & SE & Min & Max & Z & P \\
\hline Average & -.07 & .13 & -.33 & .18 & -.55 & .58 \\
Low (-1SD) & .34 & .20 & -.06 & .74 & 1.68 & .09 \\
High (+1SD) & -.48 & .18 & -.83 & -.14 & -2.75 & .01 \\
\hline
\end{tabular}




\begin{tabular}{lcccccc}
\hline & & \multicolumn{3}{c}{$95 \%$ C.I. } \\
\cline { 4 - 6 } & Estimate & $\begin{array}{c}\text { Std. } \\
\text { Deviation }\end{array}$ & Min & Max & \multirow{2}{*}{ Z } & P \\
\hline Average & .05 & .04 & -.03 & .12 & 1.27 & .21 \\
Low (-1SD) & .12 & .05 & .02 & .21 & 2.41 & .02 \\
High (+1SD) & -.02 & .05 & -.13 & .08 & -.46 & .65 \\
\hline
\end{tabular}

The moderator role of emotional stability in the relationship between paternal warmth and social coping is not significant for the average and high values of emotional stability, but it is confirmed at low levels. Thus, at low levels of emotional stability, the moderation estimate is $.12, \mathrm{Cl} 195 \%(.02, .21), \mathrm{z}$ $=2.41, p<.05$. (Table 15).

Agreeableness moderates the relationship between maternal parenting style and social coping style with an estimate of .19, CI95\% (.01, .34), z = 2.14, $p<.05$ (Table 16). The relationship is significant only for the low values of agreeableness, with an estimate of -1.54 , Cl95\% (-2.91, -
$.18), z=-2.21, p<.05$ (Table 17). In the case of the father's parenting style as well, agreeableness moderates the relationship with social coping, with an estimate of .19, Cl95\% (.01, .40), $z=2.08, p<.05$ (Table 18). For average and low values of agreeableness, the relationship between parental style and social coping is negative, and for high values, it is positive. It is important to take into consideration the fact that the values obtained for the three levels of agreeableness are not statistically significant and the results cannot be generalized (Table 19).

Table 16. Moderation estimate for agreeableness in the relationship between maternal style and social coping style

\begin{tabular}{lrrrrrr}
\hline & & & \multicolumn{2}{c}{$95 \%$ C.I. } & & \\
\cline { 4 - 5 } Matern. parenting & Estimate & SE & Min & Max & Z & P \\
A & -.54 & .49 & -1.51 & .43 & -1.09 & .27 \\
Matern. parenting * A & .28 & .09 & .09 & .47 & 2.97 & .00 \\
& .18 & .08 & .01 & .34 & 2.14 & .03 \\
\hline
\end{tabular}

Agreeableness

Table 17. Estimations of the relationship between maternal style and social coping style for different values of agreeableness

\begin{tabular}{lrrrrrr}
\hline & & & \multicolumn{2}{c}{$95 \%$ C.I. } & & \\
\cline { 4 - 6 } Average & Estimate & SE & Min & Max & Z & P \\
Low (-1SD) & -.54 & .50 & -1.53 & .44 & -1.08 & .28 \\
High (+1SD) & -1.54 & .70 & -2.91 & -.18 & -2.21 & .03 \\
& .46 & .68 & -.87 & 1.80 & .70 & .50 \\
\hline
\end{tabular}

Table 18. Moderation estimate for agreeableness in the relationship between paternal style and social coping style

\begin{tabular}{lccccccc}
\hline & & & \multicolumn{2}{c}{ 95\% C.I. } & & \\
\cline { 4 - 6 } & Estimate & SE & Min & Max & Z & P \\
\hline Patern.parenting &. .04 & .48 & -1.00 & .91 & -.09 & .93 \\
A & .30 & .10 & .12 & .50 & 3.16 & .00 \\
Pater. parenting * * A & .19 & .09 & .01 & .40 & 2.08 & .04 \\
\hline
\end{tabular}


Table 19. Estimations of the relationship between paternal style and social coping style for different values of agreeableness

\begin{tabular}{lrrrrrrr}
\hline & & & \multicolumn{2}{c}{$95 \%$ C.I. } & & \\
\cline { 5 - 7 } & Estimate & SE & Min & Max & & Z \\
\hline Average & -.05 & .50 & -1.02 & .93 & -.09 & .93 \\
Low (-1SD) & -1.14 & .72 & -2.55 & .28 & -1.60 & .11 \\
High (+1SD) & 1.05 & .73 & -.39 & 2.50 & 1.43 & .15 \\
\hline
\end{tabular}

Agreeableness weakly moderates the relationship between mother control and social coping style, in a positive direction, with an estimate of $.03, \mathrm{Cl} 95 \%(.01, .12), z=2.22, p<.05$ (Table 20). It is observed that for the low values of maternal control, the relationship is negative, but insignificant. However, at average values of agreeableness, the estimate becomes positive and significant, respectively .31, Cl95\% $(.01, .61), z=2.05, p<.05$. At high values of agreeableness, the relationship intensifies, and the estimation of the relationship reaches $.66, \mathrm{Cl} 95 \%(.20,1.12), \mathrm{z}=2.80, \mathrm{p}<.01$ (Table 21).

Table 20. Moderation estimate for agreeableness in the relationships between the dimensions of mother and father's parenting styles and social coping style

\begin{tabular}{lrrrrrrr}
\hline & & \multicolumn{5}{c}{$95 \%$ C.I. } \\
\cline { 5 - 6 } & Estimate & SE & Min & Max & Z & P \\
\hline MW * A & -.01 & .03 & -.06 & .04 & -.35 & .72 \\
MC * A & .06 & .03 & .01 & .12 & 2.22 & .03 \\
PW * A & -.01 & .01 & -.02 & .01 & -.65 & .52 \\
PC * A & .01 & .01 & -.01 & .01 & .37 & .71 \\
\hline
\end{tabular}

MW-Maternal warmth, MC-Maternal control, PW-Paternal warmth, PC-Paternal control

Table 21. Estimations of the relationship between maternal control and social coping style for different values of agreeableness

\begin{tabular}{lrrrrrrr}
\hline & & & \multicolumn{3}{c}{$95 \%$ C.I. } & & \\
\cline { 5 - 6 } Average & Estimate & SE & Min & Max & Z & P \\
Low (-1SD) & .31 & .15 & .01 & .61 & 2.05 & .04 \\
High (+1SD) & -.04 & .20 & -.43 & .36 & -.18 & .85 \\
& .66 & .24 & .20 & 1.12 & 2.80 & .00 \\
\hline
\end{tabular}

Although the intellect (or openness) did not significantly moderate the relationship between parental style (maternal or paternal) and social coping, the results reveal the moderating role of the intellect in the relationship between maternal warmth as a separate dimension of parenting and social coping. Therefore, the moderation estimate is -.06 ,
Cl95\% (-. 11, -.01), z = 1.32, $p<.05$ (Table 22). For low values of the intellect, the relationship is positive, becoming negative for the average values, but insignificant in both cases. For high values of the intellect, the relationship becomes significant, with an estimate of $-.39, \mathrm{Cl} 95 \%$ (-. .75, $-.03), z=-2.14, p<.05$ (Table 23). 
Table 22. Moderation estimates for the intellect in the relationships between the dimensions of the mother's and father's parenting styles and the social coping style

\begin{tabular}{|c|c|c|c|c|c|c|}
\hline & \multirow[b]{2}{*}{ Estimate } & \multirow[b]{2}{*}{ SE } & \multicolumn{2}{|c|}{$95 \%$ C.I. } & \multirow[b]{2}{*}{ Z } & \multirow[b]{2}{*}{$\mathbf{P}$} \\
\hline & & & Min & Max & & \\
\hline $\mathrm{MW} * 0$ & -.06 & .03 & -.11 & -.01 & -2.11 & .03 \\
\hline$M C * 0$ & .04 & .03 & -.02 & .09 & 1.32 & .19 \\
\hline PW * 0 & -.01 & .01 & -.02 & .01 & -1.02 & .31 \\
\hline$P C * 0$ & .01 & .01 & -.01 & .02 & .73 & .47 \\
\hline
\end{tabular}

Table 23. Estimations of the relationship between maternal warmth and social coping style for different intellect values

\begin{tabular}{lrrrrrrr}
\hline & & & \multicolumn{2}{c}{$95 \%$ C.I. } & & \\
\cline { 4 - 6 } Average & Estimate & SE & Min & Max & & $\mathbf{~}$ \\
\hline Low (-1SD) & -.09 & .13 & -.35 & .16 & -.74 & .46 \\
High (+1SD) & .20 & .20 & -.19 & .59 & 1.00 & .32 \\
& -.39 & .18 & -.75 & -.03 & -2.14 & .03 \\
\hline
\end{tabular}

\section{DISCUSSION}

The results showed that personality traits moderate the relationship between the parental style and personal coping style. Relationships were significant for extraversion and agreeableness as independent moderators of both maternal and paternal style in relation to social coping, as well as for emotional stability, which moderates the relationship between maternal style and social coping. Regarding the dimensions of warmth and control as independent variables, the following relationships were observed: emotional stability moderates the relationship between maternal and paternal warmth and social coping, agreeableness moderates the relationship between maternal control and social coping, and the intellect plays the role of moderator between maternal warmth and social coping. Next, we will analyze these results in turn.

These outcomes show that extraversion negatively influences the relationship of the maternal style, as well as the paternal one, with social coping. In the case of the relationship with the mother, the relationship is significant only for low values of extraversion, the interaction of the two variables correlating positively with the request for help from others. In other words, the child's introversion, in relation to the mother's parental style, is associated with an increased level of social coping. This relationship is surprising, as we would have expected a high level of extraversion to facilitate, in relation to parenting style, the use of social coping, in terms of the ease with which extroverted people make social contacts. In the case of the relationship with the father, although individually, the paternal style is not enough to correlate with social coping, the increased extraversion of the child amplifies the relationship in a negative way, making him less likely to use coping mechanisms based on support requesting social support. Evidence regarding fathers in the Romanian population claims that they promote values related to independence and individualism, more than Romanian mothers (Friedlmeier \& Friedlmeier, 2012), which, in interaction with an extroverted personality of the child, may explain the reluctance to seek the support of others. Thus, it can be expected that fathers of extroverted children will encourage them, directly or through socializing their own behaviours, to use their dynamism and assertiveness to solve their own problems, being considered more competent to do so than introverted children. We also note that the negative impact of the interaction between parenting and extraversion on social coping is stronger for fathers. We consider that in the sample used, paternal parenting styles are evenly distributed, with a higher percentage of democratic fathers, who encourage autonomy, but also negligent, who decrease trust in peers, than in the case of mothers. The fact that the maternal style, in relation to extraversion, is negatively associated with the use of social support can be an indicator of a trend among Romanian mothers to promote more and more independence. No significant results were found to support the moderating role of extraversion in the relationship between warmth and control dimensions and social coping, 
so we cannot specify what kind of approach from parents has an effect on extroverted children's coping.

Emotional stability was found as a moderator of the negative relationship between maternal style and social coping style, but only at low values. In other words, the child's high neuroticism, in relation to the way he was raised by his mother, makes him more likely to seek the help of his peers. We can expect that a person with a low level of emotional stability, with a tendency to experience especially negative emotions, will interpret the adverse situations as uncontrollable, feeling the need for external support. Moreover, people with high neuroticism had an increased negative reactivity in early childhood, which most likely manifested itself in the form of a greater need for parental support. Thus, neuroticism facilitates the effect of the parental style of increasing dependence on others for reassurance and support in the face of difficulties. More specifically, the dimension of warmth, both of the mother and of the father, in interaction with the emotional stability of the child, is negatively associated with the search for social support. This combination of factors provides the individual with the necessary resources to not feel the need to rely on others, ensuring a sufficiently high level of self-sufficiency. In conclusion, a permissive or authoritarian parenting style will prevent the development of social coping in children with increased emotional stability.

As expected, agreeableness positively moderates the relationship between maternal and paternal style and social coping. The relationship is especially significant for low values of agreeableness, which supports the assumption that people with a low level of agreeableness do not use peer support as a way of coping. Agreeableness was found as a moderator of the positive relationship between maternal control and social coping, the results showing that maternal discipline, in relation to medium and high levels of agreeableness, facilitates a high development of social coping. We can theorize that the structure and control offered by the mother, together with the obedience component of pleasant personalities, accentuates the side of dependence on others. For example, a child with high agreeableness raised by an authoritarian mother will not develop the skill to solve problems on their own, as they have not been given enough freedom to make their own decisions. Not having an appropriate level of responsibility and confidence in their own problem-solving forces, they will seek help from their peers. In line with the literature in the field of parenting, it is relevant to mention that the efficiency of social coping differs depending on the parental style of which each dimension is part. For example, both democratic and authoritarian parenting style, in interaction with the child's agreeableness, favours the use of social coping through the control component, but we can differentiate between adaptive control in democratic style and maladaptive control in authoritarian style. Thus, the request for social support can be appropriate to the requirements of the situation, such as when the person recognizes his own realistic limits and uses external help as a way of personal growth. On the other hand, the demand for social support can be a manifestation of the lack of autonomy and selfefficiency, resulting from an authoritarian rather than democratic parenting style.

Last but not least, high values of openness negatively moderated the relationship between the mother's warmth and social coping. Studies show that low openness scores correlate with low self-efficacy in the face of major, stressinducing life changes (Freund \& Wiese, 2012). Given the curiosity and diverse interests of individuals with openness to new experiences, we can expect them to obtain the necessary informational resources to develop a certain degree of self-sufficiency: skills, knowledge, abilities, etc. Along with the self-confidence offered by the maternal support of democratic and permissive mothers, they can lead to a low perceived need to ask for help from others.

\section{Limitatios and future directions}

A first limitation of the present study is the use of a crosssectional design, which does not allow the demonstration of causal relationships between variables. Therefore, a further research direction could consist in conducting a longitudinal research, which would capture the evolution of the relationship between perceived parenting and personal coping over time, as well as the influence of personality in this relationship. Moreover, the use of a self-report investigation method may limit the objectivity of the answers given by participants, due to the possibility of providing desirable answers or to memory distortions; in the future, it is recommended to use more sources in addition to selfassessment, to corroborate the results.

Another important limitation is the use of a perception questionnaire on the parenting style of the mother and father that was not adapted for the Romanian population and with an internal consistency coefficient of .60 for the mother's parental control scale and .56 for the father's parental control scale. This factor limits the possibility of generalizing the results and draws attention to the need to validate psychometric tools for evaluating parenting based on the warmth/control model for the Romanian population.

The sample used was also one of convenience, which implies a possible shortcoming in terms of demographic heterogeneity in terms of age and gender. Without sufficient respondents from each age category and each gender, it was not possible to differentiate the relationship between the perceived parental style and the personal style of coping on the basis of these criteria. Therefore, a direction for future studies could be to compile a sample of equal groups of respondents from each age category (adolescents, young people, adults, elderly), in order to capture the differences between them, as well as an equal number of women and 
men, in order to observe possible differences between the genders. Also, given the drastic socio-economic changes that Romania has gone through, an exciting continuation of this study could be the investigation of intergenerational differences in terms of coping, taking into account the impact of parenting, personality and other types of aversive events experienced by the generations that grew up before, during and after the communist period in Romania. Other demographic variables, such as cultural background, level

\section{REFERENCES}

Adams, G. R., \& Jones, R. M. (1983). Female adolescents' identity development: Age comparisons and perceived childrearing experience. Developmental Psychology, 19(2), 249. Anaya, B., \& Pérez-Edgar, K. (2019). Personality development in the context of individual traits and parenting dynamics. New Ideas in Psychology, 53, 37-46.

Baumrind, D. (1967). Child care practices anteceding three patterns of preschool behavior. Genetic Psychology Monographs. 75(1), 43-88.

Becoña, E., Martínez, Ú., Calafat, A., Juan, M., FernándezHermida, J. R., \& Secades-Villa, R. (2012). Parental styles and drug use: A review. Drugs: Education, prevention and policy, 19(1), 1-10.

Berg-Nielsen, T. S., Vikan, A., \& Dahl, A. A. (2002). Parenting related to child and parental psychopathology: A descriptive review of the literature. Clinical Child Psychology and Psychiatry, 7, 529-552.

Bolger, N., \& Zuckerman, A. (1995). A framework for studying personality in the stress process. Journal of Personality and Social Psychology, 69(5), 890.

Bretherton, I. (1990). Communication patterns, internal working models, and the intergenerational transmission of attachment relationships. Infant Mental Health Journal, 11(3), 237-252.

Cabrera, N. J., Tamis-LeMonda, C. S., Bradley, R. H., Hofferth, S., \& Lamb, M. E. (2000). Fatherhood in the twenty-first century. Child Development, 71, 127-136.

Carver, C. S., \& Connor-Smith, J. (2010). Personality and coping. Annual Review of Psychology, 61, 679-704.

Cattell, R. B. (1943). The description of personality: basic traits resolved into clusters. The Journal of Abnormal and Social Psychology, 38(4), 476-506.

Chan, S. M. (2010). Aggressive behaviour in early elementary school children: Relations to authoritarian parenting, children's negative emotionality and coping strategies. Early Child Development and Care, 180(9), 1253-1269.

Clark, R., Novak, J. D., \& Dupree, D. (2002). Relationship of perceived parenting practices to anger regulation and coping strategies in African-American adolescents. Journal of Adolescence, 25(4), 373-384. of personal and parental education, or socioeconomic status from childhood to the present, could be taken into account.

Last but not least, the research focused on two-parent families, without taking into account single-parent families, separate or reconstituted. A relevant future direction could be to analyze the impact of parenting styles in such cases and how personality can be a risk or protective factor, in order to form a more comprehensive picture of the problem.

Connor-Smith, J. K., \& Flachsbart, C. (2007). Relations between personality and coping: a meta-analysis. Journal of Personality and Social Psychology, 93(6), 1080.

Costa, P. T., \& McCrae, R. R. (1988). Personality in adulthood: a six-year longitudinal study of self-reports and spouse ratings on the NEO Personality Inventory. Journal of Personality and Social Psychology, 54(5), 853.

Costa, P. T., Jr., \& McCrae, R. R. (1985). The NEO Personality Inventory manual. Odessa, FL: Psychological Assessment Resources.

Cramer, R. J., Johnson, J. C., Crosby, J. W., Henderson, C. E., La Guardia, A. C., \& Stroud, C. H. (2015). Personality, coping and mental health among lesbian, gay, and bisexual community members. Personality and Individual Differences, 96, 272-278.

Crașovan, D. I., \& Sava, F. A. (2013). Translation, adaptations and validation on Romanian population of COPE Questionnaire for coping mechanisms analysis. Cognitie, Creier, Comportament/Cognition, Brain, Behavior, 17(1).

Darling, N., \& Steinberg, L. (1993). Parenting style as context: An integrative model. Psychological Bulletin, 113(3), 487.

Darling, N., \& Toyokawa, T. (1997). Construction and validation of the parenting style inventory II (PSI-II). Unpublished manuscript.

Dixon, R. W., Youssef, G. J., Hasking, P., Yücel, M., Jackson, A. C., \& Dowling, N. A. (2016). The relationship between gambling attitudes, involvement, and problems in adolescence: Examining the moderating role of coping strategies and parenting styles. Addictive Behaviors, 58, 4246.

Dornbusch, S. M., Ritter, P. L., Leiderman, P. H., Roberts, D. F., \& Fraleigh, M. J. (1987). The relation of parenting style to adolescent school performance, 58, 1244-1257.

Dusek, J. B., \& Danko, M. (1994). Adolescent coping styles and perceptions of parental child rearing. Journal of Adolescent Research, 9(4), 412-426.

Dusek, J. B., \& Litovsky, V. G. (1988). Maternal Employment and Adolescent Adjustment and Perceptions of Child Rearing. International Journal of Family Psychiatry, 9(2), 153-167. 
Ehnvall, A., Parker, G., Hadzi-Pavlovic, D., \& Malhi, G. (2008). Perception of rejecting and neglectful parenting in childhood relates to lifetime suicide attempts for femalesbut not for males. Acta Psychiatrica Scandinavica, 117(1), 50-56.

Eisenberg, N., Cumberland, A., \& Spinrad, T.L. (1998). Parental socialization of emotion. Psychological Inquiry, 9(4), 241-273.

Eisenberg, N., Fabes, R.A., Guthrie, I.K., \& Reiser, M. (2000). Dispositional emotionality and emotional competence. Early Education and Development, 12, 5-10.

Eysenck, S. B. G., \& Eysenck, H. J. (1963). On the dual nature of extraversion. British Journal of Social and Clinical Psychology, 2(1), 46-55.

Eysenck, H. J. (1972). Primaries or second-order factors: A critical consideration of Cattell's 16 PF battery. British Journal of Social Clinical Psychology, 1 I, 265-269.

Eysenck, H. J. (1985). The place of theory in a world of facts. In Madsen, K. B. \& Mos, L. P. (Eds), Annals of theoretical psychology, (pp. 17-72). New York: Plenum Press.

Eysenck, H. J. (1991). Dimensions of personality: 16, 5 or 3?-Criteria for a taxonomic paradigm. Personality and Individual Differences, 12(8), 773-790.

Garner, P. W. (1995). Toddlers' emotion regulation behaviors: The roles of social context and family expressiveness. The Journal of Genetic Psychology, 156(4), 417-430.

Gárriz, M., Gutiérrez, F., Peri, J. M., Baillés, E., \& Torrubia, R. (2015). Coping strategies within a personality space. Personality and Individual Differences, 80, 96-100.

Gherasim, L. R., Brumariu, L. E., \& Alim, C. L Goldberg, L. R. (1990). An alternative "description of personality": The Big-Five factor structure. Journal of Personality and Social Psychology, 59(6), 1216-1229.

Gray, M. R., \& Steinberg, L. (1999). Unpacking authoritative parenting: Reassessing a multidimensional construct. Journal of Marriage and the Family, 61, 574-587.

Grusec, J. E., \& Goodnow, J. J. (1994). Impact of parental discipline methods on the child's internalization of values: A reconceptualization of current points of view. Developmental Psychology, 30, 4 - 19.

lliescu, D., Popa, M., \& Dimache, R. (2015). Adaptarea românească a Setului International de Itemi de Personalitate: IPIP-Ro [The Romanian adaptation of the International Personality Item Pool: IPIP-Ro]. Psihologia Resurselor Umane, 13(1), 83-112.

McCrae, R. R. (2001). Traits through time. Psychological Inquiry, 12, 85-87.

McCrae, R. R., \& Costa Jr, P. T. (2008). The five-factor theory of personality.

McCrae, R. R., \& John, O. P. (1992). An introduction to the five-factor model and its applications. Journal of Personality, 60(2), 175-215.
Moscardino, U., Bertelli, C., \& Altoè, G. (2011). Culture, migration, and parenting: A comparative study of motherinfant interaction and childrearing patterns in Romanian, Romanian immigrant, and Italian families. International Journal of Developmental Science, 5(1-2), 11-25.

Nijhof, K. S., \& Engels, R. C. (2007). Parenting styles, coping strategies, and the expression of homesickness. Journal of Adolescence, 30(5), 709-720.

Parke, R.D. (1994). Progress, paradigms, and unresolved problems: A commentary on recent advances in our understanding of children's emotions. Merrill-Palmer Quarterly (1982-), 157-169.

Prinzie, P., Deković, M., van den Akker, A. L., de Haan, A. D., Stoltz, S. E. M. J., \& Jolijn Hendriks, A. A. (2012). Fathers' personality and its interaction with children's personality as predictors of perceived parenting behavior six years later. Personality and Individual Differences, 52(2), 183-189.

Prinzie, P., Stams, G. J. J. M., Dekovic', M., Reijntjes, A. H. A., \& Belsky, J. (2009). The relation between parent personality and parenting: A meta-analytic review. Journal of Personality and Social Psychology, 97, 351-362.

Rinaldi, C. M., \& Howe, N. (2012). Mothers' and fathers' parenting styles and associations with toddlers' externalizing, internalizing, and adaptive behaviors. Early Childhood Research Quarterly, 27(2), 266-273.

Robila, M., \& Krishnakumar, A. (2006). The Impact of Maternal Depression and Parenting Behaviors on Adolescents' Psychological Functioning in Romania. Journal of Child and Family Studies, 15(1), 70-81.

Roopnarine, J. L. (2004). African American and African Caribbean Fathers: Level, Quality, and Meaning of Involvement.

Roopnarine, J. L., Krishnakumar, A., Metindogan, A., \& Evans, M. (2006). Links between parenting styles, parentchild academic interaction, parent-school interaction, and early academic skills and social behaviors in young children of English-speaking Caribbean immigrants. Early Childhood Research Quarterly, 21, 238-252.

Sanchez, Y. M., Lambert, S. F., \& Cooley-Strickland, M. (2012). Adverse Life Events, Coping and Internalizing and Externalizing Behaviors in Urban African American Youth. Journal of Child and Family Studies, 22(1), 38-47.

Skinner, E. A., Edge, K., Altman, J., \& Sherwood, H. (2003). Searching for the structure of coping: a review and critique of category systems for classifying ways of coping. Psychological Bulletin, 129(2), 216.

SPSS Inc. Released 2009. PASW Statistics for Windows, Version 18.0. Chicago: SPSS Inc.

Steinberg, L. (2001). We know some things: Parentadolescent relationships in retrospect and prospect. Journal of research on adolescence, 11(1), 1-19.

The jamovi project (2020). jamovi (Version 1.2) 
Thomas, A., \& Chess, S. (1977). Temperament and development. NewYork: Brunner/Mazel

Wagner, B. M., Cohen, P., \& Brook, J. S. (1996). Parent/adolescent relationships: Moderators of the effects of stressful life events. Journal of Adolescent Research, 11(3), 347-374.

Wolfradt, U., Hempel, S., \& Miles, J. N. (2003). Perceived parenting styles, depersonalisation, anxiety and coping behaviour in adolescents. Personality and Individual Differences, 34(3), 521-532.
Zhou, Q., Wang, Y., Deng, X., Eisenberg, N., Wolchik, S. A., \& Tein, J. Y. (2008). Relations of parenting and temperament to Chinese children's experience of negative life events, coping efficacy, and externalizing problems. Child Development, 79(3), 493-513.

Zhou, Y., Li, D., Li, X., Wang, Y., \& Zhao, L. (2017). Big five personality and adolescent Internet addiction: The mediating role of coping style. Addictive Behaviors, 64, 42 48. 